Volume 5

\title{
Fair and Flexible?! Explanations Can Improve Applicant Reactions Toward Asynchronous Video Interviews
}

Johannes M. Basch

Institut für Psychologie und Pädagogik, Universität UIm

Klaus G. Melchers

Institut für Psychologie und Pädagogik, Universität UIm

Follow this and additional works at: https://scholarworks.bgsu.edu/pad

Part of the Industrial and Organizational Psychology Commons

How does access to this work benefit you? Let us know!

\section{Recommended Citation}

Basch, Johannes M. and Melchers, Klaus G. (2019) "Fair and Flexible?! Explanations Can Improve Applicant Reactions Toward Asynchronous Video Interviews," Personnel Assessment and Decisions: Number 5 : Iss. 3 , Article 2.

DOI: https://doi.org/10.25035/pad.2019.03.002

Available at: https://scholarworks.bgsu.edu/pad/vol5/iss3/2

This Main Article is brought to you for free and open access by the Journals at ScholarWorks@BGSU. It has been accepted for inclusion in Personnel Assessment and Decisions by an authorized editor of ScholarWorks@BGSU. 


\title{
Fair \& Flexible?! Explanations Can Improve Applicant Reactions Toward Asynchronous VIDEO INTERVIEWS
}

\author{
Johannes M. Basch ${ }^{1}$ and Klaus G. Melchers ${ }^{1}$ \\ 1. Institut für Psychologie und Pädagogik, Universität Ulm, Germany
}

ABSTRACT

\section{KEYWORDS}

asynchronous video interviews, applicant reactions, explanations

\begin{abstract}
Asynchronous video interviews are used more and more for the preselection of potential job candidates. However, recent research has shown that they are less accepted by applicants than face-to-face interviews. Our study aimed to identify ways to improve perceptions of video interviews by using explanations that emphasize standardization and flexibility. Our results showed that an explanation stressing the higher level of standardization improved fairness perceptions, whereas an explanation stressing the flexibility concerning interview scheduling improved perceptions of usability. Additionally, the improvement of fairness perceptions eventually influenced perceived organizational attractiveness. Furthermore, older participants accepted video interviews less. Practical implications and recommendations for future research are discussed.
\end{abstract}

Asynchronous video interviews (sometimes also called digital interviews; Langer, König, \& Krause, 2017) are one of the interview forms that have recently become more and more common as a selection tool. In these interviews, candidates are shown predefined questions on the screen, and they have to answer these questions within a specific predefined response time. Interviewees' answers are recorded via webcam and microphone, and are evaluated by the organization at another time. This means that the interview itself and the evaluation of interviewees' suitability do not take place at the same time. Despite initial evidence concerning their criterion-related validity (Gorman, Robinson, $\&$ Gamble, 2018) and their increasing use in practice due to their advantages, such as the speeding up of the staffing process and the reduction of travel costs, research concerning effects on interviewees still lags behind.

Previous studies have revealed that applicants are more sceptical about video interviews compared to face-to-face (FTF) interviews or other interview media (Blacksmith, Wilford, \& Behrend, 2016; Guchait, Ruetzler, Taylor, \& Toldi, 2014; Langer et al., 2017). This is a potential disadvantage of these interviews because negative perceptions of a selection procedure may have negative consequences for organizations when qualified applicants choose to quit the selection process or to talk badly about the organization (Hausknecht, Day, \& Thomas, 2004). Thus, the advantages of video interviews concerning the increased flexibility of the staffing process and the reduced cost might come with the price of impaired applicant perceptions. Therefore, it is important to search for ways to reconcile the practical benefits of these interviews with the needs of the applicants.

In previous studies, explanations turned out to be a cost-effective way to improve applicants' reactions to other selection procedures (Truxillo, Bodner, Bertolino, Bauer, \& Yonce, 2009). Therefore, the present study aimed to evaluate whether explanations focussing on the apparent advantages of video interviews can also improve how they are perceived by potential applicants. Specifically, we used a $2 \times 2$ design to test two different explanations for two apparent advantages: one that focused on greater standardization and one that focused on greater flexibility.

\section{Review of Previous Research and Development of Hypotheses}

\section{Applicants' Perceptions of Technology-Mediated Inter- views}

Although technology-mediated interviews in general offer many advantages, a recent meta-analysis by Black-

\author{
Corresponding author: \\ Johannes M. Basch \\ Institut für Psychologie und Pädagogik, Universität Ulm, \\ Albert-Einstein-Allee 41, D-89069 Ulm, Germany \\ Email: johannes.basch@uni-ulm.de
}

We would like to thank Carlotta Kuhn and Johanna Riester for their help with data collection. 
smith et al. (2016) found that interviewees are generally more skeptical of technology-mediated interviews compared to FTF interviews. Even though this meta-analysis did not cover research on video interviews, the general skepticism toward technology-mediated interviews from this meta-analysis was confirmed in recent studies by Langer et al. (2017), who compared perceptions of videoconference and asynchronous video interviews and by Basch, Melchers, Kegelmann, and Lieb (2018), who compared perceptions of FTF, videoconference, and asynchronous video interviews: Fairness perceptions of asynchronous video interviews were lower than of videoconference interviews, and these were lower than fairness perceptions of FTF interviews. Furthermore, Guchait et al. (2014) found that the impersonal nature of video interviews, the lack of feedback, and potential technological problems led to more skeptical views of these interviews.

In search of conceptual reasons for these differences, one might take a look at one of the most influential models to describe perceptions of and reactions to selection processes, the justice model by Gilliland (1993). It assumes that formal characteristics of the selection process, information about the decision-making process, as well as interpersonal treatment during selection play an important role for perceptions of procedural fairness. Gilliland describes different justice rules, such as the consistency of administration or the opportunity of the applicant to show his or her actual qualifications in the selection process. Furthermore, the model assumes that violations of these rules lead to lower fairness perceptions that subsequently affect applicants' reactions such as perceived organizational attractiveness or withdrawal intentions.

Although previous studies confirmed most of the predictions of Gilliland's model (cf. Hausknecht et al., 2004; McCarthy, Bauer, Truxillo, Anderson, et al., 2017; Truxillo \& Bauer, 2011), only rather few studies have taken a closer look at applicants' fairness perceptions of technology-mediated interviews and especially of asynchronous video interviews (e.g., Brenner, Ortner, \& Fay, 2016; Langer et al., 2017). Obviously, some justice rules are violated in video interviews, such as the rule to allow for two-way communication. However, other rules like the consistency of administration are fulfilled to a larger degree in comparison to typical FTF interviews.

\section{Explanations as a Means to Improve Applicants' Reac- tions}

In light of Gilliland (1993), one might use explanations to positively influence applicants' fairness perceptions to reconcile the discrepancy between the advantages of and applicant reactions towards video interviews. Explanations might be provided before a selection procedure and may contain different kinds of information. Some explanations emphasize the job relevance of a selection procedure (e.g.,
Melchers \& Körner, 2019), others provide details on the selection process, for example, what happens at what time (e.g., Truxillo, Bauer, Campion, \& Paronto, 2002). The effects of explanations have been explored in various studies, and it has been found that in addition to improving perceptions of the selection process explanations can also lead to higher organizational attractiveness and improved behavioral intentions by applicants (Bauer, Maertz, Dolen, \& Campion, 1998; McCarthy, Bauer, Truxillo, Campion, et al., 2017; Truxillo et al., 2009).

With respect to technology-mediated interviews, we are aware of only one study by Langer, König, and Fitili (2018) that examined the effects of providing additional information on reactions toward an interview in which a virtual character acted as the interviewer and in which automated algorithms analyzed nonverbal behavior. This additional information made the procedure more transparent to participants but turned out to be a "double-edged sword" (Langer et al., 2018, p. 19): Although it had positive effects on some of Gilliland's (1993) fairness rules and a positive indirect effect on organizational attractiveness, this effect was counterbalanced by a negative direct effect. However, the information provided by Langer et al. did not emphasize any specific advantages of the interview but rather explained the specific features of the automated algorithms.

Instead of information about features of the automated algorithms as used by Langer et al. (2018), explanations might instead emphasize advantages of asynchronous video interviews such as their higher degree of standardization, because all interviews are administered in the same way and every interviewee has the same opportunity to perform. Unfortunately, a potential risk concerning an explanation related to standardization is that previous research found that highly standardized interviews tend to be less well-accepted than less standardized interviews (Conway \& Peneno, 1999; Kohn \& Dipboye, 1998). However, Chapman and Rowe (2002) found that higher interview standardization was seen more favorable in a videoconference interview than in a FTF interview. Furthermore, an explanation that specifically stresses equal treatment of all applicants instead of the technical aspects of standardization should evoke more positive reactions. Thus, according to Gilliland's (1993) model, such an explanation on standardization should increase applicants' global fairness perceptions of these interviews as well as specific perceptions concerning the consistency of the selection process and perceived opportunity to perform (because performance evaluations should be biased less by irrelevant factors). Therefore, we suggest the following hypothesis:

Hypothesis 1: Giving an explanation on standardization has a positive effect on (a) global fairness perceptions of asynchronous video interviews as well as on (b) perceived consistency and (c) perceived opportunity to perform. 
Another theoretical approach that is relevant concerning the acceptance of new technology in selection is the technology acceptance model (TAM) by Davis (1989). According to this model, the perceived usefulness and the perceived ease of use of novel technologies lead to positive attitudes toward these technologies and to their actual usage. In line with this, Brenner et al. (2016) found that perceived ease of use and perceived usefulness go along with more positive attitudes toward asynchronous video interviews.

Given that asynchronous video interviews are highly flexible with respect to time and place, one can also emphasize this advantage in an explanation. Accordingly, we also assume that a corresponding explanation might not only have positive effects on perceived ease of use and perceived usefulness of video interviews but also on perceived flexibility (Davis, 1989):

Hypothesis 2: Giving an explanation on flexibility has a positive effect on (a) perceived flexibility, (b) perceived ease of use, and (c) perceived usefulness of asynchronous video interviews.

In line with Gilliland's (1993) model and corresponding meta-analytic evidence (Hausknecht et al., 2004), applicants are also likely to react more positively during a selection process when they perceive the selection procedure as more fair. Accordingly, an explanation concerning standardization of asynchronous interviews might indirectly affect applicant reactions via its effect on fairness perceptions. Thus, a corresponding explanation might lead to higher perceptions of organizational attractiveness, which captures aspects such as the perceived general attractiveness and the prestige of an organization but also important behavioral intentions by applicants (cf. Model 1 in Figure 1). Accordingly, we assume the following mediation effect:

Hypotheses 3: Fairness perceptions mediate the effect of the explanation concerning standardization on (a) general attractiveness, (b) behavioral intentions, and (c) prestige.

Finally, given Brenner et al.'s (2016) finding that the perceived usability of asynchronous video interviews was related to attitudes toward them, we assume that usability perceptions (i.e., perceived flexibility as well as perceived usefulness and perceived ease of use from the TAM) of asynchronous interviews may also lead to more positive applicant reactions (cf. Model 2 in Figure 1). Therefore, we predict:

Hypotheses 4: Perceived flexibility, perceived ease of use, and perceived usefulness mediate the effect of the explanation concerning flexibility on (a) general attractiveness, (b) behavioral intentions, and (c) prestige.

\section{METHOD}

\section{Sample}

Our sample consisted of 203 German-speaking working individuals (65\% female) aged between 18 and $65(M$ $=28.67$ years, $S D=11.66)$ who were recruited via posts from our work group in different groups in social media like Facebook or who were approached directly with emails containing the link to an online questionnaire. Data from another 152 individuals who abandoned the questionnaire before the end were excluded from our analyses. Concerning their highest academic degree, $49 \%$ held a university-entrance diploma and $31 \%$ a university degree. Of the participants, $3 \%$ were self-employed, $47 \%$ held a regular job, and the rest was holding so-called mini jobs. On average, participants were working 20.52 hours per week $(S D=$ 16.73 ) and on average they had already participated in 6.38 job interviews; $25 \%$ had already experienced a technology-mediated interview, and $2 \%$ had already taken part in an asynchronous video interview. There was no incentive for participation in our study.

\section{Procedure}

The study was administered via an online questionnaire. After completing demographic items, participants were asked to imagine that they had applied for a job and would now go through the first selection procedure. In the next step, they read an invitation email from an organization, in which they were invited to complete an asynchronous interview. We used a $2 \times 2$ (Standardization $\times$ Flexibility) design with four different versions of this email to which the participants were randomly assigned (see Appendix A). Two groups each received an explanation either concerning standardization or flexibility of video interviews. The other two groups received either no explanation or both explanations.

Participants were told to read through the email carefully. Then, they were shown sample questions and screenshots from a video interview, which described what such an interview actually looks like and how it works. The screenshots were made during a simulated asynchronous video interview using the Interview Suite of the German provider viasto (www.viasto.com). Finally, participants had to answer questions concerning fairness perceptions, perceived usability of this interview, and applicant reactions variables.

\section{Measures}

All items are provided in Appendix B. Answers were provided on 5-point rating scales ranging from $1=$ strongly disagree to $5=$ strongly agree. To determine reliabilities for the different measures, we followed suggestions by Cho (2016) and calculated reliabilities for correlated factor models. The reliability estimates therefore represent $\rho_{\mathrm{CF}} \mathrm{s}$ for correlated factors and represent a more appropriate alterna- 
FIGURE 1.

Mediation models suggested in Hypotheses 3 and 4.

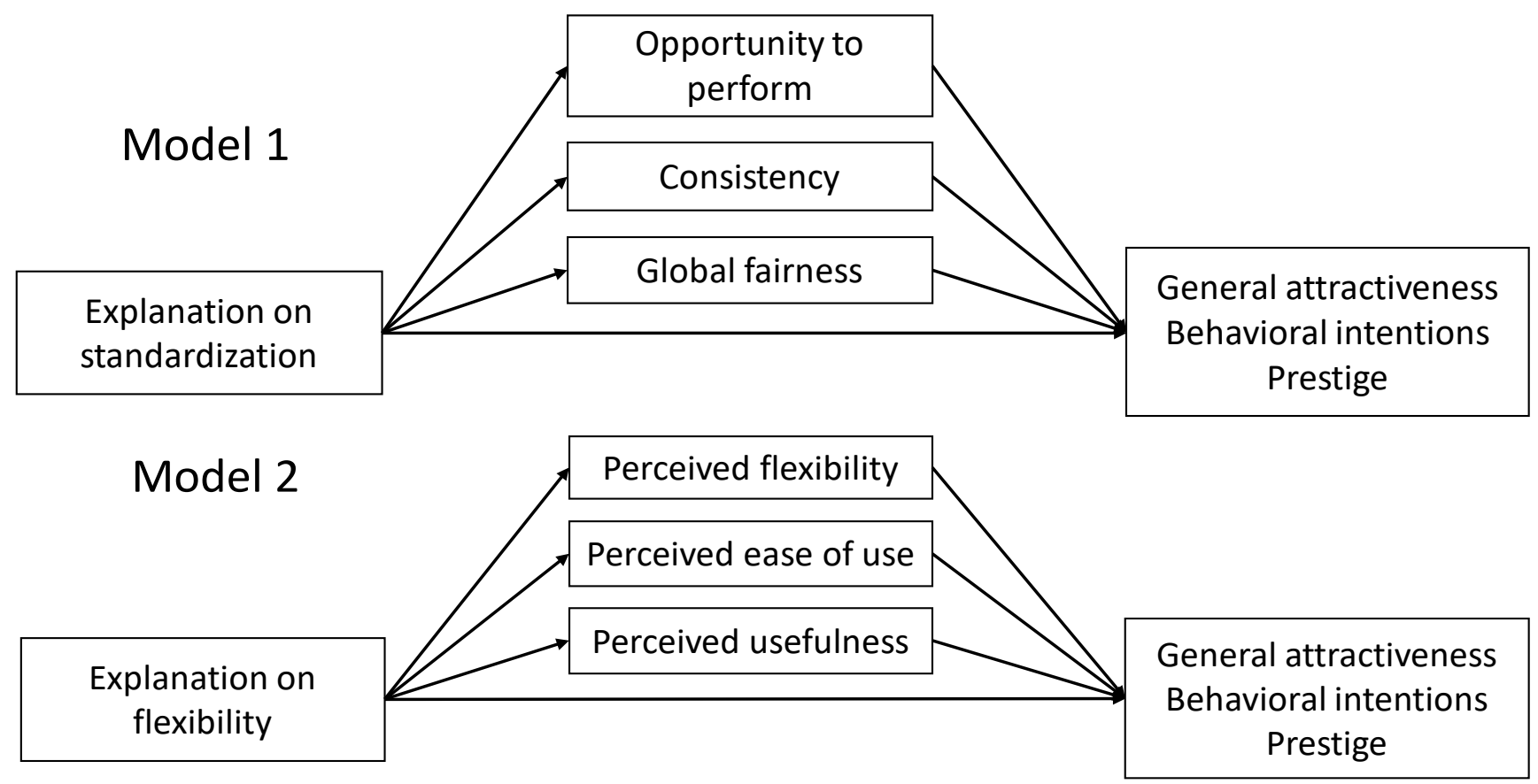

tive to coefficient alpha.

Fairness perceptions. We used three subscales from the Selection Procedural Justice Scale (Bauer et al., 2001). These three subscales represented opportunity to perform (four items, $\rho_{\mathrm{CF}}=.91$ ), consistency (three items, $\rho_{\mathrm{CF}}=.82$ ), and global fairness (two items, $\rho_{\mathrm{CF}}=.84$ ). A confirmatory factor analysis (CFA) with three correlated factors that evaluated the distinctiveness of these subscales had good fit, $\mathrm{CFI}=.98$, TFI $=.98$, RMSEA $=.06$. In contrast, a single-factor model had poor fit, $\mathrm{CFI}=.66$, TFI $=.55$, RMSEA $=.25$.

Usability perceptions. To measure perceived ease of use, we used five items $\left(\rho_{\mathrm{CF}}=.83\right)$ from an adapted scale from the TAM (Davis, 1989) and two items to measure perceived usefulness $\left(\rho_{\mathrm{CF}}=.84\right)$. In addition, we developed three items to measure perceived flexibility $\left(\rho_{\mathrm{CF}}=.80\right)$. We evaluated the distinctiveness of these subscales with a CFA specifying three correlated factors. Even though the fit was not brilliant, $\mathrm{CFI}=.91$, TFI $=.87$, RMSEA $=.11$, it was markedly better than for an alternative single-factor model, $\mathrm{CFI}=.66, \mathrm{TFI}=.56, \mathrm{RMSEA}=.20$.

Applicant reactions. To measure applicant reactions, we used the organizational attractiveness scale developed by Highhouse, Lievens, and Sinar (2003). It contains three subscales capturing general attractiveness (five items, $\rho_{\mathrm{CF}}=$ .89), behavioral intentions such as the intention to accept a potential job offer (five items, $\rho_{\mathrm{CF}}=.81$ ), and prestige (five items, $\rho_{\mathrm{CF}}=.86$ ). In line with Highhouse et al., a model with three correlated factors yielded a better fit, $\mathrm{CFI}=.96$, TFI $=.95$, $\mathrm{RMSEA}=.07$, than a single-factor model, $\mathrm{CFI}=.81$, $\mathrm{TFI}=.78, \mathrm{RMSEA}=.13$.

\section{RESULTS}

\section{Preliminary Analyses}

Table 1 shows correlations and descriptive information for all study variables. As can be seen there, older participants had more negative perceptions concerning global fairness and concerning usability of asynchronous video interviews.

ANOVAs were used to evaluate the comparability of the four experimental groups. These showed that the groups did not differ concerning sex, educational level, and job or interview experience, all $F_{\mathrm{s}}<1$, all $p \mathrm{~s}>.39$. However, we found a marginally significant effect for age $F(3,199)=$ $2.33, p=.08$. Furthermore, as can be seen in Table 1, age was significantly correlated with the flexibility explanation, $r=-.14, p=.04$, meaning that participants who received an explanation on flexibility were younger.

\section{Evaluation of Effects of the Explanations}

The means for all dependent variables for the four groups are shown in Table 2. To evaluate Hypothesis 1, we conducted a $2 \times 2($ Standardization $\times$ Flexibility) multi- 
variate analysis of variance (MANOVA) that included all dependent variables for Hypothesis 1 (i.e., opportunity to perform, consistency, global fairness). In line with Hypothesis 1 that giving an explanation on standardization has a positive effect on fairness perceptions of asynchronous video interviews, the MANOVA only revealed a significant effect for the explanation on standardization, Wilk's $\lambda=.93$, $F(3,197)=5.21, p=.002$. To find the source of this significant effect, we conducted separate $2 \times 2$ ANOVAs for each dependent variable. We found significant effects for global fairness (Hypothesis 1a), $F(1,199)=14.83, p<.001$, and for opportunity to perform (Hypothesis 1b), $F(1,199)=$ $5.26, p=.02$. Expressed as Cohen's $d \mathrm{~s}$, these effects represent small ( $d=.32$ for opportunity to perform) to moderate $(d=.55$ for global fairness) effects (Cohen, 1992). There were no qualitative differences in the results when age was taken into account as a covariate. None of the remaining main effects or interaction terms reached significance (cf. Table 2).

Hypothesis 2 stated that giving an explanation on flexibility would have a positive effect on perceived flexibility, perceived ease of use, and perceived usefulness. In line with this, a $2 \times 2$ MANOVA for these three dependant variables only revealed a significant effect for flexibility, Wilk's $\lambda=$ $.96, F(3,197)=2.91, p=.04$. Separate ANOVAs revealed a significant effect for perceived flexibility (Hypothesis $2 \mathrm{a}$ ), $F(1,199)=4.37, p=.04$, and perceived ease of use (Hypothesis $2 \mathrm{~b}), F(1,199)=8.15, p=.005$, which represent small to moderate effects $(d=.29$ for perceived flexibility and $d=.41$ for perceived ease of use). None of the remaining main effects or interaction terms reached significance. As age was significantly correlated with the flexibility explanation, we additionally conducted a $2 \times 2$ MANCOVA with age as a covariate. The main effect for the flexibility explanation failed to reach significance, Wilk's $\lambda=.97$, $F(3,196)=2.11, p=.10$. However, separate ANOVAs still revealed significant or marginally significant effects for perceived ease of use, $F(4,198)=5.93, p=.02$, and perceived flexibility, $F(4,198)=3.16, p=.08$. Given the directional nature of our hypothesis, we consider these results as moderate support for Hypothesis 2.

\section{Test of Mediation Hypotheses}

To evaluate Hypothesis 3 and 4, we conducted separate path analyses for the different applicant reaction variables to test the models shown in Figure 1. To do so we used the R-package lavaan (Rosseel, 2012), and we determined the significance of the direct and indirect effects by using the PROCESS macro by Hayes (2018). The corresponding results are shown in Table 3.

Hypothesis 3 predicted that fairness perceptions mediate the effect of providing an explanation concerning standardization on applicant reactions (Model 1 in Figure 1). In line with this prediction, when all three mediators were considered together, the total indirect effect was significant (Hypotheses 3a-c; cf. Table 3). Inspection of the separate paths showed that global fairness was the strongest mediator representing between .12 and .21 of the total indirect effects.

Finally, Hypothesis 4 stated that usability perceptions mediate the effect of an explanation concerning flexibility on applicant reactions (Model 2 in Figure 1). When all three mediators were considered together, only a significant indirect effect on general attractiveness (Hypothesis 4a) was found. For the other applicant reaction variables the total indirect effect did not reach significance. Therefore, only Hypothesis $4 \mathrm{a}$ was supported.

\section{DISCUSSION}

To the best of our knowledge, this is the first study to examine the effects of giving explanations on advantages of video interviews on applicants' perceptions and reactions. By doing so, our study responds to calls for more research on new technologies in personnel selection (Blacksmith et al., 2016).

The results of our study show that explanations emphasizing the advantages of standardization and flexibility of video interviews can have positive effects on fairness perceptions and perceived usability and thereby also indirectly on applicant reactions. This is in line with previous evidence on the beneficial effects of explanations concerning other selection procedures (McCarthy, Bauer, Truxillo, Anderson, et al., 2017; Truxillo et al., 2009).

As assumed, an explanation on standardization improved fairness perceptions of video interviews. Several of Gilliland's (1993) justice rules refer to aspects related to standardization, such as the independence of biases or the same chance for all applicants to show their qualifications. Standardization therefore goes along with a focus on relevant information, controllability, and a transparent selection procedure.

Even though the standardization explanation significantly improved fairness perceptions in general, it is surprising that it did not affect perceived consistency, although the aspects emphasized in the explanation directly addressed the facets of this subscale. Nevertheless, in contrast to studies that examined effects of interview structure on applicant reactions and that found negative reactions toward structured interviews compared to less structured interviews (Chapman \& Zweig, 2005; Kohn \& Dipboye, 1998), it is important to note that the explanation in our study generally had a positive effect on fairness perceptions and also indirectly on applicant reactions. However, this effect is similar to Chapman and Rowe (2002) who found that participants accepted higher structure in videoconference interviews more than they did in FTF interviews. Additionally, it is also noteworthy that we even found larger effects of expla- 


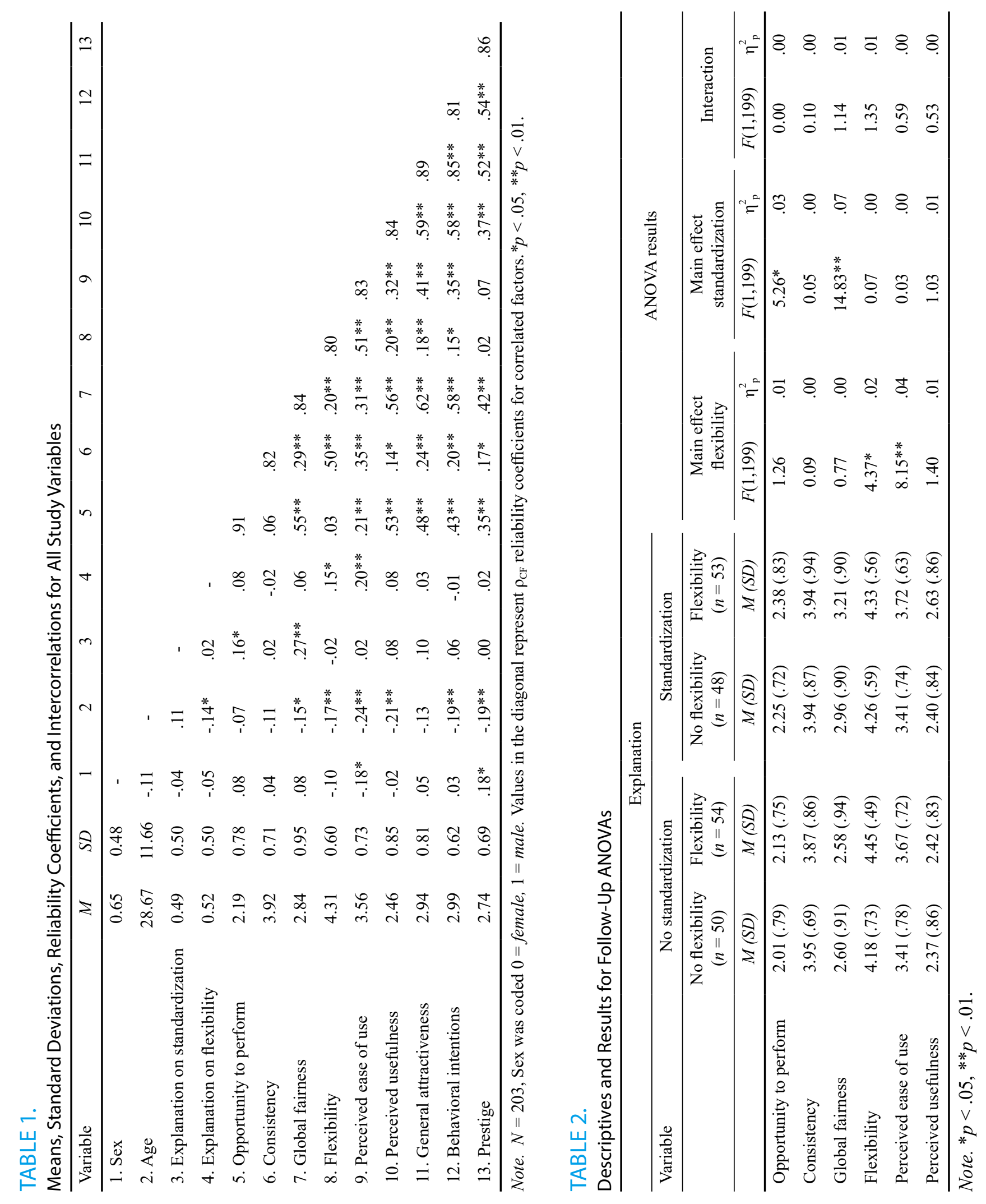


TABLE 3.

Direct, Indirect, and Total Effects of the Explanation on Standardization and Flexibility on Applicant Reactions

\begin{tabular}{|c|c|c|c|c|c|}
\hline \multirow[t]{2}{*}{ Dependent Variable } & \multicolumn{2}{|c|}{ Direct effect } & \multicolumn{2}{|c|}{ Indirect effect } & \multirow{2}{*}{ Total effect } \\
\hline & Effect & $S E$ & Effect & $S E$ & \\
\hline \multicolumn{6}{|c|}{ Effects of explanation concerning standardization ${ }^{\text {a }}$} \\
\hline General attractiveness & -0.11 & 0.09 & $0.27 *$ & 0.08 & 0.16 \\
\hline Behavioral intentions & -0.12 & 0.07 & $0.20 *$ & 0.06 & 0.08 \\
\hline Prestige & -0.16 & 0.09 & $0.16^{*}$ & 0.06 & 0.00 \\
\hline \multicolumn{6}{|c|}{ Effects of explanation concerning flexibility ${ }^{b}$} \\
\hline General attractiveness & -0.10 & 0.09 & $0.15^{*}$ & 0.07 & 0.05 \\
\hline Behavioral intentions & -0.11 & 0.07 & 0.10 & 0.06 & -0.01 \\
\hline Prestige & -0.01 & 0.06 & 0.03 & 0.04 & 0.02 \\
\hline
\end{tabular}

nations than the meta-analysis by Truxillo et al. (2009).

Besides previous studies that found that explanations can improve fairness perceptions of selection procedures (McCarthy, Bauer, Truxillo, Anderson, et al., 2017), our study also sheds new light on the fact that explanations can also improve perceptions beyond fairness such as perceived flexibility or perceptions of usability that are related to Davis' (1989) technology acceptance model. Furthermore, these perceptions can indirectly affect the perceived attractiveness of an organization in addition to fairness perceptions.

Taken together, our results are therefore more encouraging than the recent findings by Langer et al. (2018) who found that simply providing more information on technological aspects can be a double-edged sword. Instead, we found that explanations that stress advantageous aspects of asynchronous video interviews can help to mitigate applicants' usual skeptical view of these interviews (Basch et al., 2018; Langer et al., 2017).

In addition to our hypotheses, we also found an effect of participants' age on perceptions of video interviews. Specifically, older participants perceived video interviews as less fair and also less useful. This is in line with previous findings that the acceptance of new technologies decreases with age (Hauk, Hüffmeier, \& Krumm, 2018). However, although using age as a covariate mitigated the positive effects of the flexibility explanation, they did not disappear completely.

\section{Limitations}

A limitation of the present study is that our participants did not actually complete an asynchronous video interview but that they provided their views of these interviews on the basis of screenshots and detailed descriptions. Given that it is long known that greater familiarity leads to more positive evaluations of an object (Bornstein, 1989), it is conceivable that interviewees who actually complete a video interview would evaluate it more positively than the present participants. Nevertheless, on the basis of evidence by Truxillo et al. (2009) that the effects of explanations are stronger in high-stakes field settings than in simulated settings, it might well be that the present effects represent a conservative estimate of the actual impact of explanations on perceptions of video interviews.

\section{Practical Implications and Lines for Future Research}

To attenuate or prevent negative reactions by applicants, organizations using video interviews to preselect candidates should use explanations that emphasize the advantages of these interviews. These explanations are a cost-effective way to give applicants an understanding of the reasons for the usage of these interviews. In addition to the usual focus on fairness aspects (e.g., Truxillo et al., 2009), an explanation on beneficial aspects concerning the administration of video interviews also seems reasonable to make advantages more salient to applicants. Furthermore, this could be even more relevant for older applicants, who generally see new technologies more skeptical.

For future research on applicant reactions, our findings related to technology acceptance also suggest that it might be valuable to consider other aspects that go beyond the usual scope of fairness theories. In this regard, it might for example be helpful to use qualitative approaches such as Guchait et al. (2014) to find out what applicants like or 
dislike most about asynchronous video interviews, which would then allow to specifically address these aspects in an explanation. Furthermore, we suggest investigating whether an explanation also improves interviewees' motivation and thereby their performance in interviews similar to the effect that Truxillo et al. (2009) found for ability tests. Moreover, it would be interesting to examine different ways an explanation might be presented. For example, many video interview platforms make it possible to show a welcome video before the actual interview. Providing the explanation orally within this welcome video might even amplify the beneficial effects, because this might help to ensure that applicants do not overlook it. Research on realistic job previews, for instance, found that an oral presentation of relevant information tends to have stronger effects than a written presentation (Earnest, Allen, \& Landis, 2011).

Finally, additional research that goes beyond applicant reactions is necessary. For instance, further research is needed that evaluates possible reasons for the performance differences between different interview media (e.g., Blacksmith et al., 2016; Langer et al., 2017). Even though a study by Gorman et al. (2018) suggests that video interviews can predict job performance, more research concerning criterion-related validity is necessary, because that study relied on self-ratings.

\section{Conclusion}

In summary, providing information about the advantages of video interviews can improve perceptions of these interviews, which have been low in previous studies. Focusing on the apparent benefits of video interviews can thereby help to improve applicant reactions to video interviews and to prevent negative effects for organizations that use such interviews.

\section{REFERENCES}

Basch, J. M., Melchers, K. G., Kegelmann, J., \& Lieb, L. (2018, June). Are they comparable? Reactions to technology-mediated vs. face-to-face interviews. Paper presented at the 5th ENESER meeting. Edinburgh, UK.

Bauer, T. N., Maertz, C. P., Dolen, M. R., \& Campion, M. A. (1998). Longitudinal assessment of applicant reactions to employment testing and test outcome feedback. Journal of Applied Psychology, 83, 892-903.

Bauer, T. N., Truxillo, D. M., Sanchez, R. J., Craig, J. M., Ferrara, P., \& Campion, M. A. (2001). Applicant reactions to selection: Development of the Selection Procedural Justice Scale (SPJS). Personnel Psychology, 54, 387-419. doi:10.1111/j.17446570.2001.tb00097.x

Blacksmith, N., Wilford, J. C., \& Behrend, T. S. (2016). Technology in the employment interview: A meta-analysis and future research agenda. Personnel Assessment and Decisions, 2, 12-20. doi:10.25035/pad.2016.002

Bornstein, R. F. (1989). Exposure and affect: Overview and meta-analysis of research, 1968-1987. Psychological Bulletin, 106, 265-289. doi:10.1037/0033-2909.106.2.265

Brenner, F., Ortner, T. M., \& Fay, D. (2016). Asynchronous video interviewing as a new technology in personnel selection: The applicant's point of view. Frontiers in Psychology, 7:863, 1-11. doi:10.3389/fpsyg.2016.00863

Chapman, D. S., \& Rowe, P. M. (2002). The influence of videoconference technology and interview structure on the recruiting function of the employment interview: A field experiment. International Journal of Selection and Assessment, 10, 185-197. doi:10.1111/1468-2389.00208

Chapman, D. S., \& Zweig, D. I. (2005). Developing a nomological network for interview structure: Antecedents and consequences of the structured selection interview. Personnel Psychology, 58, 673-702. doi:10.1111/j.17446570.2005.00516.x

Cho, E. (2016). Making reliability reliable: A systematic approach to reliability coefficients. Organizational Research Methods, 19, 651-682. doi: 10.1177/1094428116656239

Cohen, J. (1992). A power primer. Psychological Bulletin, 112, 155-159. doi:10.1037/0033-2909.112.1.155

Conway, J. M., \& Peneno, G. M. (1999). Comparing structured interview question types: Construct validity and applicant reactions. Journal of Business and Psychology, 13, 485-506.

Davis, F. (1989). Perceived usefulness, perceived ease of use and user acceptance of information technology. MIS Quarterly, 13, 319-340.

Earnest, D. R., Allen, D. G., \& Landis, R. S. (2011). Mechanisms linking realistic job previews with turnover: A meta-analytic path analysis. Personnel Psychology, 64, 865-897. doi:10.1111/j.1744-6570.2011.01230.x

Gilliland, S. W. (1993). The perceived fairness of selection systems: An organizational justice perspective. Academy of Management Review, 18, 694-734. doi:10.5465/ AMR.1993.9402210155

Gorman, C. A., Robinson, J., \& Gamble, J. S. (2018). An investigation into the validity of asynchronous web-based video employment-interview ratings. Consulting Psychology Journal: Practice and Research, 70, 129-146. doi:10.1037/ cpb0000102

Guchait, P., Ruetzler, T., Taylor, J., \& Toldi, N. (2014). Video interviewing: A potential selection tool for hospitality managers-a study to understand applicant perspective. International Journal of Hospitality Management, 36, 90-100. doi:10.1016/j.ijhm.2013.08.004

Hauk, N., Hüffmeier, J., \& Krumm, S. (2018). Ready to be a silver surfer? A meta-analysis on the relationship between chronological age and technology acceptance. Computers in Human Behavior, 84, 304-319. doi:10.1016/ j.chb.2018.01.020

Hausknecht, J. P., Day, D. V., \& Thomas, S. C. (2004). Applicant reactions to selection procedures: An updated model and meta-analysis. Personnel Psychology, 57, 639-683. doi:10.1111/ j.1744-6570.2004.00003.x 
Hayes, A. F. (2018). Introduction to mediation, moderation, and conditional process analysis: A regression-based approach (2nd ed.). New York, NY: Guilford Press.

Highhouse, S., Lievens, F., \& Sinar, E. F. (2003). Measuring attraction to organizations. Educational and Psychological Measurement, 63, 986-1001.

Kohn, L. S., \& Dipboye, R. L. (1998). The effects of interview structure on recruiting outcomes. Journal of Applied Social Psychology, 28, 821-843. doi:10.1111/j.1559-1816.1998. tb01733.x

Langer, M., König, C. J., \& Fitili, A. (2018). Information as a double-edged sword: The role of computer experience and information on applicant reactions towards novel technologies for personnel selection. Computers in Human Behavior, 81, 19-30. doi:10.1016/j.chb.2017.11.036

Langer, M., König, C. J., \& Krause, K. (2017). Examining digital interviews for personnel selection: Applicant reactions and interviewer ratings. International Journal of Selection and Assessment, 25, 371-382. doi:10.1111/ijsa.12191

McCarthy, J. M., Bauer, T. N., Truxillo, D. M., Anderson, N. R., Costa, A. C., \& Ahmed, S. M. (2017). Applicant perspectives during selection: A review addressing "so what?," "what's new?," and "where to next?" Journal of Management, 43, 1693-1725. doi:10.1177/0149206316681846

McCarthy, J. M., Bauer, T. N., Truxillo, D. M., Campion, M. C., Van Iddekinge, C. H., \& Campion, M. A. (2017). Using pre-test explanations to improve test-taker reactions: Testing a set of "wise" interventions. Organizational Behavior and Human Decision Processes, 141, 43-56. doi:10.1016/j.obhdp.2017.04.002

Melchers, K. G., \& Körner, B. (2019). Is it possible to improve test takers' perceptions of ability tests by providing an explanation? Journal of Personnel Psychology, 18, 1-9. doi:10.1027/1866-5888/a000212

Rosseel. (2012). lavaan: An R package for structural equation modeling. Journal of Statistical Software, 48, 1-36.

Truxillo, D. M., \& Bauer, T. N. (2011). Perceived fairness of hiring practices. In S. Zedeck (Ed.), APA handbook of industrial and organizational psychology (Vol. 2, pp. 379-398). Washington, DC: American Psychologcial Association.

Truxillo, D. M., Bauer, T. N., Campion, M. A., \& Paronto, M. E. (2002). Selection fairness information and applicant reactions: $A$ longitudinal field study. Journal of Applied Psychology, 87, 1020-1031. doi:10.1037/0021-9010.87.6.1020

Truxillo, D. M., Bodner, T. E., Bertolino, M., Bauer, T. N., \& Yonce, C. A. (2009). Effects of explanations on applicant reactions: A meta-analytic review. International Journal of Selection and Assessment, 17, 346-361. doi:10.1111/j.14682389.2009.00478.x

RECEIVED 10/16/18 ACCEPTED 05/09/19 


\section{Appendix A}

The following information is a translation of the email that was shown to participants as their respective interview invitation. The original materials in the study were in German.

Dear Mr./Mrs. Mustermann,

Welcome and thank you for your application!

As part of our selection process, we ask you first to complete a video interview so that we get a personal impression of you. All you need is a computer with a standard web browser, a webcam, and a microphone. You can also use a mobile device (iOS or Android).

(Additional information for all participants who received an explanation on flexibility:

An advantage of video interviews compared to traditional job interviews is the high flexibility for applicants, that is, that you can complete the interview at any time and any place with Internet access. In this way, you can complete the interview at a time that suits your needs and matches your daily routine. This is especially beneficial because it makes it easier to reconcile the interview with your other commitments, which makes finding appointments much easier. In addition, you save time and costs compared to conventional job interviews, which would be associated with the otherwise necessary journey.)

(Additional information for all participants who received an explanation on standardization:

An/Another advantage of video interviews compared to traditional job interviews is the high level of structure and standardization. This means that each candidate gets the same questions in the same order and has the same time to prepare and answer. This equal treatment of all applicants means that physical appearances, sympathy, or coincidences can influence the interview result less. In addition, all applicants will be evaluated according to the same criteria and the overall assessment will be standardized. This supports a more objective assessment of all applicants based on their actual responses.)

In our video interview, questions are presented on the screen, which you can then answer via a microphone and a webcam. Afterwards, the interviews will be evaluated by us at a different point in time.

The link to the interview can be found below. The interview does not start immediately after registration. You can first familiarize yourself with the software, check your equipment, and complete a demo interview. Once you have finished this, you are free to start the actual video interview or to do it later within the next 7 days.

We wish you good luck and look forward to your video interview! 


\section{Appendix B}

Items used to measure the different variables. For all items, German translations were used in our study.

\begin{tabular}{|c|c|}
\hline \multicolumn{2}{|c|}{ Items used for the current study } \\
\hline \multirow{4}{*}{ Opportunity to perform } & I would be able to show what I can do in such an interview. \\
\hline & I could really show my skills and abilities in such an interview. \\
\hline & Such an interview would allow me to show my job skills. \\
\hline & Such an interview would give applicants the opportunity to show what they really can do. \\
\hline \multirow{3}{*}{ Consistency } & This interview would be conducted for all applicants in the same way. \\
\hline & $\begin{array}{l}\text { There would be no differences in the way the interview would be conducted with different } \\
\text { applicants. }\end{array}$ \\
\hline & In such an interview there is no difference how applicants are treated. \\
\hline \multirow{2}{*}{ Global fairness } & I believe that such an interview is a fair procedure to select people. \\
\hline & I believe that this interview itself is fair. \\
\hline \multirow{3}{*}{ Perceived flexibility } & Such an interview offers a wide range of flexibility concerning time and place. \\
\hline & Finding a fitting interview appointment would be very easy with this interview method. \\
\hline & $\begin{array}{l}\text { The whole process of this interview (finding an appointment, completing the interview) } \\
\text { would be very easy. }\end{array}$ \\
\hline \multirow{5}{*}{ Perceived ease of use } & Completing a video interview would be easy for me. \\
\hline & I would find it easy to get a program for video interviews to do what I want it to do. \\
\hline & My interaction with a program for video interviews would be clear and understandable. \\
\hline & I would find a video interview flexible to interact with. \\
\hline & I would find it easy to complete a video interview. \\
\hline \multirow[t]{2}{*}{ Perceived usefulness } & $\begin{array}{l}\text { Video interviews would make it easier for me to show a good performance in a job } \\
\text { interview. }\end{array}$ \\
\hline & Video interviews would make applicants' lives easier. \\
\hline \multirow{6}{*}{ General attractiveness } & For me, this company would be a good place to work. \\
\hline & I would not be interested in this company except as a last resort. (reverse coded) \\
\hline & This company is attractive to me as a place for employment. \\
\hline & I am interested in learning more about this company. \\
\hline & A job at this company is very appealing to me. \\
\hline & I would exert a great deal of effort to work for this company. \\
\hline \multirow{5}{*}{ Intentions to pursue } & I would accept a job offer from this company. \\
\hline & I would make this company one of my first choices as an employer. \\
\hline & If this company invited me for a job interview, I would go. \\
\hline & I would exert a great deal of effort to work for this company. \\
\hline & I would recommend this company to a friend looking for a job. \\
\hline \multirow{5}{*}{ Prestige } & Employees are probably proud to say they work at this company. \\
\hline & This is a reputable company to work for. \\
\hline & This company probably has a reputation as being an excellent employer. \\
\hline & I would find this company a prestigious place to work. \\
\hline & There are probably many who would like to work at this company. \\
\hline
\end{tabular}

